\title{
Genistein Enhances the Promoting Effects of Exercise on Anti-Oxidant and Anti- Inflammation Balance and Cardiomyopathy in the Ovariectomized Diabetic Rat
}

\section{Farzaneh Nazari-Serenjeh}

Payame Noor University

Seyyed Alireza Vafaie

Islamic Azad University Sanandaj Branch

Maryam Khajvand-Abedini

Hamadan University of Medical Sciences

Amir Mohammad Salehi

Hamadan University of Medical Sciences

Mohammad Mohammadi

Hamadan University of Medical Sciences

Parisa Habibi ( D Dr.habibi2007@gmail.com)

Hamadan University of Medical Sciences https://orcid.org/0000-0002-5311-8630

\section{Research Article}

Keywords: Ovariectomy, Diabetes, MiRNA-133, Exercise, Genistein.

Posted Date: August 19th, 2021

DOI: https://doi.org/10.21203/rs.3.rs-811808/v1

License: (c) (1) This work is licensed under a Creative Commons Attribution 4.0 International License.

Read Full License 


\section{Abstract}

Purpose: These experiments aimed to analyze the effects of genistein and/or exercise on the expression of miRNA-133, IGF-1, and Bcl-2, Bax plus oxidative stress and inflammation markers in the heart of diabetic ovariectomized rats.

Methods: Animals were divided into seven groups $(n=8)$ : control, sham, ovariectomy $(O V X)$, diabetic ovariectomized (OD), and diabetic ovariectomized with eight weeks of genistein administration (ODG) and with eight weeks of swimming training (ODS) and with eight weeks of both of them (ODGS). High-fat nutrition and low dose streptozotocin injection were used for induction of diabetes. The effect of those treatments was evaluated by measuring lipid profiles, miRNA-133 gene expression, and Bcl-2, Bax, and IGF-1 protein expression levels. Inflammation and oxidative stress markers levels were also measured.

Results: ovariectomy down-regulated cardiac miRNA-133, IGF-1, and Bcl-2 expression levels and increased MDA, OSI, TOS, TNF- $a$, and NF-KB levels plus a reduction in TAC. Diabetes induced an additive effect on the above-measured factors. Genistein improved oxidative and inflammation conditions and upregulated miRNA-133, Bcl-2, and IGF-1 expression in OD rats. Genistein also enhanced the positive effect of exercise on miRNA-133, Bcl-2, and IGF-1expression in the heart, along with a reduction in Bax. The combined intervention was associated with improvement in oxidative and inflammation conditions. Histological observation showed some abnormality in cardiac tissue, which was improved by genistein or/and exercise treatment.

Conclusion: genistein or/and exercise as a natural replacement therapy could improve diabetic-induced cardiac complications within the heart of ovariectomized rats.

\section{Introduction}

Diabetes has been recognized as a significant risk factor for cardiovascular disease in young and postmenopausal women (Boudina and Abel 2010; Daghigh et al. 2017; Ghosh and Katare 2018). During and after menopause, the incidence of diabetes increases in women (Daghigh et al. 2017).

Diabetic cardiomyopathy is the most common cause of death in a patient with diabetes. It is a complex disease, and many physiological factors are implicated in the pathogenesis of the disease (Boudina and Abel 2010; Ghosh and Katare 2018). Many studies showed that diabetes is associated with increased inflammatory and oxidative stress markers that lead to endothelial dysfunction, cell death, and cardiovascular remodeling (Khullar et al. 2010). Moreover, it has been shown that oxidative stress contributes to the increased cardiovascular dysfunction associated with estrogen deficiency (White et al. 2010). MicroRNAs (miRNAs) are small non-coding RNA molecules that have a vital role in regulating protein-coding gene expression (O'Brien et al. 2018). MiRNA-133, as a specific cardiac/skeletal miRNA, has a critical role in cardiac development and pathophysiology (Katz et al. 2016; Li et al. 2018). It is well established that altered expression of miRNA-133 is also implicated in diabetic cardiomyopathy (Liu and Liu 2017; Shantikumar et al. 2012). Several studies indicate that cell death-regulating Bcl-2 family and 
insulin-like growth factor-1 (IGF-1) proteins are mediator molecules involved in miRNA-133-induced cardiac protection (Habibi et al. 2016b; Izarra et al. 2014). The Bcl-2 family of proteins regulates cell death signaling at the mitochondrial level (Youle and Strasser 2008), and IGF-1 as a mediator of growth hormone reduces oxidative stress, fibrosis, and apoptosis in the heart (Wang et al. 2016). Dysregulation of miRNA-133, Bcl-2, and IGF-1 receptor expression in the heart of ovariectomized or diabetic rats has been confirmed in previous studies (Chen et al. 2005; Habibi et al. 2020; Habibi et al. 2016b).

Genistein is a natural phytoestrogen with estrogenic effects (Dixon and Ferreira 2002). It has been reported that genistein has beneficial effects on menopause, cardiovascular disease, and diabetes in women (Crisafulli et al. 2005; Gilbert and Liu 2013; Thangavel et al. 2019; Weng et al. 2019). Previous studies have been revealed that oxidative stress and inflammatory signaling pathways mediate Genistein-induced effects (Gupta et al. 2015; Weng et al. 2019). Genistein also influences microRNAs and mRNAs expression (Chiyomaru et al. 2013; Xia et al. 2012; Xu et al. 2013). Along whit a diet rich in antioxidants, physical exercise is well known that diminish oxidative stress and improves diabetesinduced cardiac complications (Kanter et al. 2017; Mahmoud 2017; Naderi et al. 2015). Also, the modulation of microRNAs by exercising and its association with heart remodeling have been recently reviewed by researchers (Ellison et al. 2011; Fernandes et al. 2012).

To our knowledge, the effect of genistein treatment alone and in combination with exercise training in managing the cardiac disease of diabetic women after ovarian hormone deprivation has not been entirely investigated. Therefore, the present study aimed to evaluate the effect of genistein alone or in combination with exercise training on the cardiac expression of oxidative/inflammation biomarkers (MDA, OSI, TOS, TNF- $\alpha$ and NF-KB) and miRNA-133, IGF-1, and Bcl-2 in the diabetic ovariectomized rats.

\section{Materials And Methods \\ 2.1. Animals}

The animal procedures were approved by the local animal care committee of Tabriz University of medical sciences and were conducted using institutional guidelines for the care and use of laboratory animals (NIH, publication no. 85 - 23, revised 2010; European Communities Directive 86/609/EEC). Female Wistar rats were obtained from the Experimental Animal Center, Medical Faculty, Tabriz University, Tabriz, Iran (180-220 g). The rats were maintained (seven days before the initiation of the experiment) under temperature- $\left(22 \pm 2^{\circ} \mathrm{C}\right)$ and light-controlled (12-h light/12-h dark cycle) room and had free access to food and drinking water.

\subsection{Experimental design}

The rats were randomly divided into following the seven groups (8 rats in each group). Group 1 and 2 were Control and sham-operated. Five groups of the ovariectomized (OVX) rats were as following: Group 3: ovariectomized rats (OVX); Group 4: sedentary diabetic ovariectomized rats (OD); Group 5: swimming training-diabetic ovariectomized rats (ODS); Group 6: Genistein treated-diabetic ovariectomized rats 
(ODG) and Group 7: genistein treatment with swimming training diabetic ovariectomized rats (ODGS). Simultaneously with high-fat feeding, administration of genistein and swimming training was performed for eight weeks. It should be considered that Genistein (Sigma, U.S.A.) was injected subcutaneously (1 $\mu \mathrm{g} / \mathrm{kg} /$ day) (Daghigh et al. 2018).

\subsection{Ovariectomy}

For ovariectomy surgery, the rats were weighed and anesthesia induced by an intraperitoneal administration of a combination of xylazine $(10 \mathrm{mg} / \mathrm{kg})$ and ketamine $(50 \mathrm{mg} / \mathrm{kg})$. Then, the rat's skin was shaved over the abdominal midline and disinfected. A 1.5 to $2 \mathrm{~cm}$ longitudinal incision (from the second to fifth lumbar vertebrae; in the left lateral position). Next, the oviduct was ligated, ovaries removed, silk suture, abdominal muscle tissue, and the skin sutured. Sham surgery consisted of the exact procedures without placement of the ligatures and ovary removal (Habibi et al. 2016a).

\subsection{Induction of type 2 diabetes}

One week after ovariectomy, all rats within the diabetic groups were fed with a high-fat diet $(58 \%$ fat, $17 \%$ carbohydrate, and $25 \%$ protein) provided ad libitum for 30 days. On the last day, the rats fasted overnight and then a low dose of STZ ( $35 \mathrm{mg} / \mathrm{kg}$, intraperitoneally) was injected in a $0.1 \mathrm{M}$ citrate buffer ( $\mathrm{pH} 4.5)$. The Control group received intraperitoneal administration of citrate buffer. Fasting blood glucose level was measured at $72 \mathrm{~h}$ after STZ Injection with a glucometer to show hyperglycemia. Rats with a fasting blood glucose level over $200 \mathrm{mg} / \mathrm{dl}$ were considered diabetic rats (Habibi et al. 2020).

\subsection{Exercise (swimming) training protocol}

As previously described (Habibi et al. 2016b; Habibi et al. 2017), after becoming familiarized with the swimming bath (5-20 min/day, for five successive days), the rats swam for six days/wk. (60 min/day) for eight weeks. All determinations were made in exercised rats $24 \mathrm{~h}$ after their last exercise session (Daghigh et al. 2018).

\subsection{Biochemical analyses}

The rats were kept fasting overnight (16h) with free access to water, and the blood samples were collected from the eye plexus. For measurement of blood glucose, an Accu-Chek Active glucometer was used. Serum samples were analyzed for plasma insulin level, HbA1C, triglycerides (TG), total cholesterol (TC), high-density lipoprotein (HDL), low-density lipoprotein (LDL), using a sandwich ELISA kit (Millipore, for insulin) and a commercial diagnostic kit (Randox, UK, for lipid profile assessment).

\subsection{Total antioxidant capacity assay}

Total antioxidant capacity (TAC) in the heart tissues homogenate was determined by measuring their potential to reduce Fe III to Fe II established as named ferric-reducing antioxidant potential (FRAP) test. As an antioxidant activity, the antioxidants present in the medium start to produce Fe II-TPTZ from ferric tripyridyltriazine (Fe III-TPTZ, present in medium). Measuring the change in absorption at $593 \mathrm{~nm}$ 
determined the reduction from ferric (colorless) to the ferrous form (blue colored). FeSO4.7H2O (aqueous solution) was used as a standard.

\subsection{Total oxidant status assay}

Total oxidant status (TOS) was detected in heart tissue homogenate according to Heidarisasan et al. (2018). Production of ferric ion and xylenol orange formed a colored complex (maximal absorption at $560 \mathrm{~nm}$ ) which is detected and calibrated to hydrogen peroxide. Oxidative Stress Index (OSI) was calculated using the following formula: TOS/TAS $\times 100$.

\subsection{Lipid peroxidation assay}

Measurement of malondialdehyde (MDA) concentration (as the end product of the polyunsaturated fatty acids oxidation) in the heart tissue homogenate indicates the extent of lipid peroxidation. The fluorescence intensity of a complex produced due to the reaction of MDA. With thiobarbituric acid (TBA) was determined by using a spectrophotometer (at $515 \mathrm{~nm}$ excitation and 553nm emission wavelength). In order to assess the concentrations of TBA-MDA adducts in samples, the standard curve of 1,1,3,3tetraethoxypropan solutions was used.

\subsection{Molecular Analysis}

\subsubsection{RNA isolation and therefore the cDNA synthesis}

At the end of the experiments (eight weeks), the rats were sacrificed, and their hearts were separated. Total RNA was extracted from the left ventricle of hearts using RNX-Plus solution kit (Fermentase, Cinagen Co. Iran) and miR-amp kit (parsgenome Co. Iran). The RNA purity indices, such as A260/280, were quantified by the NanoDrop 1000 (Thermo Scientific, Waltham, and Mass), and gel electrophoresis with GelRed (Biotium, Hayward, California) evaluated the integrity of the samples. Quantitative assessment of the IGF-1, Bcl-2 genes, and miRNA-133 expressions was done by a real-time polymerase chain reaction. Primers' sequences for every gene were mentioned in Table 1. 
Table 1

The primers sequences for each of genes

\begin{tabular}{|lll|}
\hline Genes & Accession number & Primers Sequence $^{\text {a }}$ \\
\hline IGF-1 & NM- 001082477 & F: AAG CCT ACA AAG TCA GCT CG \\
& R: GGT CTT GTT TCC TGC ACT TC \\
\hline Bcl-2 & NM_016993.1 & $\begin{array}{l}\text { F: F: CGGGAGAACAGGGTATGA } \\
\text { R: CAGGCTGGAAGGAGAAGAT }\end{array}$ \\
\hline & NM_017008.4 & F: TGCCGCCTGGAGAAACCTGC \\
& R: TGAGAGCAATGCCAGCCCCA \\
\hline miRNA-133 & MIMAT0017124 & AGCUGGUAAAAUGGACCAAAU \\
\hline miRNA-191a & MIMAT0000866 & CAACGGAAUCCCAAAGCAGCUG \\
\hline $\begin{array}{l}\text { a Sequences were derived from NCBI (www.ncbi.nlm.nih.gov) } \\
\text { b Sequences were derived from miRBase (www.mirbase.org) }\end{array}$
\end{tabular}

The housekeeping gene - 3-phosphate dehydrogenase (GAPDH) mRNA samples and miRNA-191 for microRNA samples (internal control) were used to normalize the number of PCR products. For CDNA Synthesis, $1 \mu$ lof total RNA was reverse transcribed $\left(10 \mathrm{~min}\right.$ at $\left.25^{\circ} \mathrm{C}\right)$ to synthesize single-strand cDNA using Revert Aid M-MuLV reverse transcriptase $(1 \mu \mathrm{l})$, DNase I $(1 \mu \mathrm{l})$ and random hexamer primers $(1 \mu \mathrm{l})$, dNTPs $(2 \mu \mathrm{l})$, and RiboLockRNase-inhibitor $(0.25 \mu \mathrm{l})$. The reaction mixture was incubated for $60 \mathrm{~min}$ at $42^{\circ} \mathrm{C}, 5 \mathrm{~min}$ at $70^{\circ} \mathrm{C}$, and $5 \mathrm{~min}$ at $4^{\circ} \mathrm{C}$. Besides, synthesis of cDNA in microRNA sample performance in keeping with the miR-amp kit (parsgenome Co. Iran).

\subsubsection{Real-time quantitative PCR}

A master mixture of $25 \mu \mathrm{l}$ containing $12.5 \mu \mathrm{l}$ SYBR Green PCR Master Mix (Jena Bioscience, Germany), one $\mu \mathrm{l}$ forward primer, one $\mu \mathrm{l}$ reverse primer, and $8.5 \mu \mathrm{l}$ water was prepared to carry out real-time PCR. Two microliters of reverse-transcribed cDNA were then added to the PCR master mix to attain a final volume of $25 \mu \mathrm{l}$. Furthermore, to test amplification accuracy, we included a negative control in each run by eliminating the cDNA sample within the tube.

The PCR protocol was used on the real-time PCR machine (Rotor-Gene 3000) in three steps, including 1initial denaturation $\left(10 \mathrm{~min}\right.$ at $\left.95^{\circ} \mathrm{C}\right) ; 2$ - a three-step amplification program $\left(15 \mathrm{~s}\right.$ at $95^{\circ} \mathrm{C}$ followed by $30 \mathrm{~s}$ at $60^{\circ} \mathrm{C}$ for miRNA-133 and IGF- 1 genes and $30 \mathrm{~s}$ at $58^{\circ} \mathrm{C}$ for Bcl-2 gene and $30 \mathrm{~s}$ at $72^{\circ} \mathrm{C}$ ) repeated 40 times; and step three-melting curve analysis ( 1 cycle: 72 to $95^{\circ} \mathrm{C}$ with temperature transition rate $1^{\circ} \mathrm{C} / \mathrm{sec}$ for five sec). All runs were performed in duplicates. Real-time quantification was monitored by measuring 
the rise in fluorescence caused by binding of the SYBR Green dye to double-stranded DNA at the end of every amplification cycle. The relative amount of mRNA for every target gene was calculated based on its threshold cycle (Ct) compared to the $\mathrm{Ct}$ of the housekeeping (reference) gene (GAPDH). The relative quantification was performed by 2-(DDCt) method. The specificity of the PCR reactions was verified by producing a melting curve analysis, following that gel electrophoresis, stained with GelRed (Biotium, Hayward, California).

\subsection{Elisa}

Bax, Bcl2, IGF-1, NF-KB, and TNF-a protein concentrations in heart tissue were measured using enzymelinked immunosorbent assay ELISA method using Apotarget Apoptosis kit (Camarillo, California 93012USA). The bovine serum albumin was used to normalize data to the levels of protein evaluated by the Lowery method.

\subsection{Histological Analysis}

As previously reported (Habibi et al. 2016a), the paraffin section of the cardiac tissues (about five $\mu \mathrm{m}$ thicknesses) were stained with hematoxylin \& eosin and periodic acid Schiff (PAS) to evaluate changes of histology and glycogen granules within the sarcoplasm of cardiomyocytes under an optical microscope (Olympus BH-2, Tokyo, Japan).

\subsection{Statistical analysis}

All the data are expressed as mean \pm S.E.M. Significant differences between the groups were determined with SPSS 22.0 software (SPSS Inc., Chicago, IL, USA) using one-way ANOVA, and the group means were compared by Tukey's test. The minimum level of significance was fixed at $P<0.05$.

\section{Results}

In the analysis of the research results, because there was no difference between the results of the control group and the results of the sham group, we do not report the results of the control group.

\section{3,1 . Body and heart Weight}

As shown in Table 2, after eight weeks, the OD rats had a significantly decreased body weight (BW) compared with the sham group $(p<0.05)$. However, HW to BW ratio in the OD rats was significantly higher than those within the other groups. Table 2 also shows that the HW to BW ratio was significantly different in the ODS and ODSG groups compared with sham and ODG groups. 
Table 2

Effects of ovariectomy, diabetes and exercise on body and heart weight of different studied groups

\begin{tabular}{|c|c|c|c|}
\hline & BW final ( g ) & $\mathrm{HW}(\mathrm{mg})$ & $\mathrm{HW} / \mathrm{BW}(\mathrm{mg} / \mathrm{g})$ \\
\hline Sham & $261.87 \pm 4.87$ & $896 \pm 0.02$ & $3.42 \pm 0.133$ \\
\hline OVX & $273.88 \pm 2.55$ & $967 \pm 0.02$ & $3.53 \pm 0.016$ \\
\hline OD & $196.00 \pm 4.0^{*}$ & $867 \pm 0.02$ & $4.42 \pm 0.235^{\star}$ \\
\hline ODS & $259.88 \pm 3.54$ & $983 \pm 0.03$ & $3.78 \pm 0.252^{\star \star}, \#$ \\
\hline ODG & $260.87 \pm 4.37$ & $869 \pm 0.01$ & $3.33 \pm 0.116$ \\
\hline ODGS & $259.50 \pm 5.41$ & $971 \pm 0.03$ & $3.74 \pm 0.184^{* \star}, \#$ \\
\hline \multicolumn{4}{|c|}{$\begin{array}{l}\text { OVX: ovariectomized group, OD: ovariectomized with 8-weeks diabetic group. ODS: ovariectomized } \\
\text { diabetic group with 8-weeks swimming training. ODG: ovariectomized diabetic group with 8-weeks } \\
\text { genistein administration. ODGS: ovariectomized diabetic group with 8-weeks swimming training an } \\
\text { genistein administration. }\end{array}$} \\
\hline \multicolumn{4}{|c|}{ Data are expressed as mean \pm SEM. } \\
\hline \multicolumn{4}{|c|}{${ }^{*} \mathrm{p}<0.05$ vs. Sham, OVX, ODG, ODS \& ODGS; } \\
\hline \multicolumn{4}{|c|}{${ }^{* *} p<0.05$ vs. Sham; } \\
\hline \multicolumn{4}{|c|}{${ }^{\#} p<0.05$ vs. ODG. } \\
\hline
\end{tabular}

\section{3, 2. Biochemically results}

Glucose homeostasis parameters are shown in Table 3. A significant elevation in fasting blood glucose (FBG) level was observed in OD rats when compared to sham, OVX, and OD groups $(p<0.05)$. Moreover, FBG was increased in the ODS rats compared to the sham, 0 , and OD group $(p<0.05)$. Furthermore, OD rats showed a significant increase in insulin levels compared to sham, 0 , and ODS groups and ODS rats compared to 0 and sham rats $(p<0.05)$. Moreover, plasma glycosylated hemoglobin $(\mathrm{HbA} 1 \mathrm{c})$ increased in the OD group compared to sham, 0 , and ODS groups $(p<0.05)$, although this elevation was not statistically significant. 
Table 3

Parameters of glucose homeostasis of different studied groups at the end of the study

\begin{tabular}{|c|c|c|c|}
\hline & $\begin{array}{l}\text { Fasting blood glucose } \\
\text { (mg/dl) }\end{array}$ & $\begin{array}{l}\text { Serum insulin } \\
(\mu \mathrm{lU} / \mathrm{mL})\end{array}$ & $\begin{array}{l}\text { Plasma glycosylated hemoglobin } \\
\text { (\%) }\end{array}$ \\
\hline Sham & $98.20 \pm 2.13$ & $4.3 \pm 1.8$ & $4.380 \pm 0.57$ \\
\hline OVX & $109.00 \pm 1.87$ & $13.2 \pm 1.1^{\star *}$ & $4.920 \pm 0.63$ \\
\hline OD & $269.00 \pm 13.26^{*}$ & $28.9 \pm 1.5^{\star}$ & $5.960 \pm 0.60$ \\
\hline ODS & $160.00 \pm 10.83 \#$ & $24.9 \pm 1.6^{*}$ & $4.620 \pm 0.67$ \\
\hline ODG & $155.80 \pm 9.85$ & $22.9 \pm 1.3^{*}$ & $4.780 \pm 0.51$ \\
\hline ODGS & $110.80 \pm 9.01$ & $9.3 \pm 1.7$ & $4.540 \pm 0.50$ \\
\hline \multicolumn{4}{|c|}{$\begin{array}{l}\text { OVX: ovariectomized group, OD: ovariectomized with 8-weeks diabetic group. ODS: ovariectomized } \\
\text { diabetic group with 8-weeks swimming training. ODG: ovariectomized diabetic group with 8-weeks } \\
\text { genistein administration. ODGS: ovariectomized diabetic group with 8-weeks swimming training and } \\
\text { genistein administration. }\end{array}$} \\
\hline \multicolumn{4}{|c|}{ Data are expressed as mean \pm SEM. } \\
\hline \multicolumn{4}{|c|}{${ }^{*} p<0.05$ vs. Sham \& OVX; } \\
\hline \multicolumn{4}{|c|}{${ }^{* *} \mathrm{p}<0.05$ vs. Sham \& OD; } \\
\hline \multicolumn{4}{|c|}{${ }^{\#} p<0.05$ vs. Sham, OVX \& OD. } \\
\hline
\end{tabular}

The plasma lipid profiles are shown in Fig. 1. The triglycerides (TG), total cholesterol (TC), and lowdensity lipoprotein (LDL) levels of $O$ and $O D$ rats were significantly higher. In contrast, high-density lipoprotein $(\mathrm{HDL})$ was significantly lower than sham control rats $(\mathrm{p}<0.05)$. No significant change was observed in other groups TG, TC, LDL, and HDL compared with correspondence control groups.

\section{3, 3. Effect of genistein treatment and/or swimming training in diabetic ovariectomized rats on total antioxidant capacity, total oxidant status, and oxidative stress index}

The heart homogenates total antioxidant capacity (TAC) levels are shown in Fig. 2A. In heart homogenates TAC values, a significant decrease was observed in OVX and OD groups compared to the sham control group $(p<0.001)$. An increasing effect was observed in heart homogenates of OD rats receiving swimming training compared with the OD group $(p<0.001)$. A significant increase in TAC was recorded in genistein treated OD rats as compared with OVX $(p<0.05)$ and OD $(p<0.001)$ group. The TAC value of heart tissues in the ODGS group was more significant in comparison with OVX $(p<0.001)$ and OD $(p<0.001)$ group. 
The heart homogenates total oxidant status (TOS) are shown in Fig. 2B. Heart total oxidant status in the OVX $(p<0.01)$ and OD $(p<0.001)$ rats increased significantly as compared to the sham control group $(p<$ 0.01 and $p<0.05$, respectively). The heart TOS in ODS ( $<<0.001$ as compared with OD group), ODG ( $p<$ 0.001 as compared with OD group and $p<0.05$ as compared with OVX group) and also ODGS. $(p<0.001$ as compared with OD group and $p<0.01$ as compared with OVX group)-treated rats were significantly reduced.

Moreover, oxidative stress index (OSI, Fig. 2C) were increased in the OVX and OD rats (compared to the sham group, $p<0.001)$ and decreased in ODS ( $p<0.001$ as compared with OD group), ODG ( $<0.001$ as compared with OD group and $p<0.01$ as compared with OVX group) and ODGS. ( $p<0.001$ as compared with OD and OVX groups) groups.

\section{3, 4. Effects of genistein treatment and/or swimming training in diabetic ovariectomized rats on lipid peroxidation (MDA concentration).}

Figure 3 shows the results of heart tissues MDA concentrations. The MDA level of OVX $(p<0.001)$ and OD $(p<0.001)$ groups were significantly higher than the sham control group. In addition, ODS $(p<0.001$ as compared with OD group), ODG ( $P<0.05$ as compared with OVX and $p<0.001$ as compared with OD group) and ODGS ( $p<0.01$ as compared with OVX and $p<0.001$ as compared with OD group) treated rats showed lower MDA concentrations.

\section{3, 5. Effect of genistein treatment and/or swimming training in diabetic ovariectomized rats on Bax, Bcl2, IGF-1, NF-KB, and IGF-1 protein concentrations}

The concentration of IGF-1 protein was assessed in rat heart tissues by the ELISA method and shown in Fig. 4A. Ovariectomy leads to decreased IGF-1 protein concentration in the heart tissues compared with the sham group $(p<0.001)$. In ovariectomized rats, a diabetic condition caused a reduction in IGF-1 protein concentrations $(p<0.001)$. In the heart tissues of ODS $(p<0.001$ as compared with OVX), ODG ( $p$ $<0.001$ as compared with OVX and $p<0.01$ as compared with OD group) and ODGS. ( $<<0.001$ as compared with OVX and $p<0.01$ as compared with OD group) animal group significant increase in the IGF-1 level was observed.

The protein concentration of $\mathrm{Bcl}-2$ was assessed in rat heart tissues by ELISA (Fig. 4B). Compared with the sham and OD group, ovariectomy (OVX group) decreased BCL-2 level in the heart tissues $(p<0.001)$. A significant decrease in Bcl-2 level was observed in the OD compared to the sham group $(p<0.001)$. Protein concentration of $\mathrm{Bcl}-2$ in the heart tissues was higher in the ODS $(\mathrm{p}<0.001$ as compared with OVX), ODG ( $p<0.001$ as compared with OVX and $p<0.001$ as compared with OD group), and also ODGS ( $p<0.001$ as compared with OVX and $p<0.001$ as compared with OD group) groups.

The concentration of Bax protein was assessed in rat heart tissues by the ELISA method (Fig. 4C). As shown in Fig. 4C, ovariectomy resulted in a significant increase in Bax protein levels of the heart tissues when compared with sham and OD groups $(p<0.001)$. Further analysis indicated that the concentration 
of Bax was increased in the OD animals compared with the sham group $(p<0.001)$. Moreover, in ODS ( $p$ $<0.001$ as compared with OVX), ODG ( $p<0.001$ as compared with OVX and $p<0.001$ as compared with OD group) and ODGS. ( $p<0.001$ as compared with OVX and $p<0.001$ as compared with OD group) groups, the protein concentration of Bax in the heart tissues was lower.

As shown in Fig. 4D and 4E, NF-KB and TNF- a protein concentrations were markedly increased in heart tissues of OVFX and OD groups in comparison with sham groups $(p<0.001)$. However, genistein $(p<$ 0.001 as compared with OVX and $p<0.001$ as compared with OD group) and exercise ( $p<0.001$ as compared with OD group) treatment alone or in combination ( $p<0.001$ as compared with OVX and $p<$ 0.001 as compared with OD group) reduces the NF-KB and TNF- a protein concentrations.

\section{3, 6. Effect of genistein treatment and/or swimming training in diabetic ovariectomized rats on miRNA- 133 expression}

The level of heart miRNA-133 expression under the treatments was examined by real-time RT-PCR (Fig. 5). As shown in Fig. 5, the miRNA-133 expression was significantly decreased in the heart tissues of ovariectomized rats compared with the sham control group $(p<0.001)$. Moreover, compared with OVX and sham rats, expression levels of miRNA-133 were lower in the heart tissues of OD rats $(p<0.001)$. An increase in the level of heart miRNA-133 expression also was observed in ODS ( $<<0.001$ as compared with OVX), ODG ( $p<0.001$ as compared with OVX and $p<0.001$ as compared with OD group), and also ODSG ( $p<0.001$ as compared with OVX and $p<0.001$ as compared with OD group) groups.

\section{3, 7. Histological results}

Table 4 and Fig. 6A-L demonstrated the histological changes of routine and OVX, OD, ODS, ODG, and ODSG rats. Genistein or swimming treatment caused decreased myocardial fibrosis, leukocyte infiltration, and disorganization myocardial. Based on Fig. 6A, cardiac muscle cells were incorporated in standard features of myocytes, including a cross-striated banding model, nucleus with oval, vesicular, and centrally placed pale staining appearance intercalated disks found at the interface among the neighboring cardiac muscle cells in the sham animal group. Furthermore, in the OVX animal group, the sarcoplasm of myocyte was striped and acidophilus and was organized on an unvarying basis. However, this study specified that numerous variations such as structural protection integrity were comparable with variations observed in the sham animal group. Other conclusions revealed an intensification of dense fibrosis and necrotic cell compactness and outstanding importance in the number of connective tissue elements in the OVX group (Fig. 6B). Histological changes in the heart of OD were similar to the OVX animal group but significantly worse (Fig. $6 \mathrm{C}$ ). The findings of this study also declared that the genistein administration (Fig. 6D) or swimming training (Fig. 6E) improved a series of variations, including the reduced tendency in the fibrotic area and necrotic cell density and normalized quantity of connective tissue in the ODG and ODS animal group. However, in the ODGS animal group, further, the improvement of variations, including the reduced tendency in the fibrotic area and necrotic cell density and normalized quantity of connective tissue, were seen (Fig. 6F). Besides, the histological evaluations of heart tissue in PAS analysis showed a constant and homogeneous granule of glycogen in the sarcoplasm of 
cardiomyocytes in the sham animal group (Fig. 6G). However, fragmentation and irregular accumulation of glycogen granules were seen in the OVX animal group (Fig. $6 \mathrm{H})$, and these changes in the heart of the OD animal group were worse (Fig. 6l). Genistein administration (Fig. 6J) or swimming training (Fig. 6K) decreased fragmentation of glycogen granules in these groups compared with OVX and OD animal groups in the sarcoplasm of cardiomyocytes. Also, in the ODGS group, further, improvement was observed and further decreased fragmentation of glycogen granules in the sarcoplasm of cardiomyocytes (Fig. 6L).

Table 4

Histological changes of the heart (H\&E) in different studied groups

\begin{tabular}{|c|c|c|c|c|c|c|}
\hline & Sham & ovx & OD & ODS & ODG & ODGS \\
\hline $\begin{array}{l}\text { Cardiac fibers } \\
\text { hypertrophy }\end{array}$ & 0 & $\begin{array}{l}6.60 \pm \\
0.50 \star\end{array}$ & $\begin{array}{l}9.20 \pm \\
0.37\end{array}$ & $\begin{array}{l}4.00 \pm \\
0.44^{\star \star}\end{array}$ & $\begin{array}{l}3.90 \pm \\
0.49 \star \star\end{array}$ & $\begin{array}{l}1.50 \pm \\
0.39\end{array}$ \\
\hline Myocardial fibrosis & 0 & $\begin{array}{l}5.20 \pm \\
0.58^{*}\end{array}$ & $\begin{array}{l}9.00 \pm \\
0.31\end{array}$ & $\begin{array}{l}3.40 \pm \\
0.81^{\star \star}\end{array}$ & $\begin{array}{l}3.20 \pm \\
0.70^{\star \star}\end{array}$ & $\begin{array}{l}1.34 \pm \\
0.51\end{array}$ \\
\hline Leukocyte Infiltration & 0 & $\begin{array}{l}5.00 \pm \\
0.37 \star\end{array}$ & $\begin{array}{l}7.80 \pm \\
0.24\end{array}$ & $\begin{array}{l}2.20 \pm \\
0.37 \star \star\end{array}$ & $\begin{array}{l}2.10 \pm \\
0.47^{\star \star}\end{array}$ & $\begin{array}{l}1.77 \pm \\
0.26\end{array}$ \\
\hline $\begin{array}{l}\text { Disorganization } \\
\text { Myocardial }\end{array}$ & 0 & $\begin{array}{l}5.40 \pm \\
0.60^{\star}\end{array}$ & $\begin{array}{l}9.40 \pm \\
0.40\end{array}$ & $\begin{array}{l}2.80 \pm \\
0.58^{\star \star}\end{array}$ & $\begin{array}{l}2.70 \pm \\
0.49^{\star \star \star}\end{array}$ & $\begin{array}{l}1.57 \pm \\
0.23\end{array}$ \\
\hline \multicolumn{7}{|l|}{ fibers disarray } \\
\hline $\begin{array}{l}\text { Cardiomyocyte } \\
\text { vacuolation }\end{array}$ & 0 & $\begin{array}{l}5.00 \pm \\
0.31^{*}\end{array}$ & $\begin{array}{l}7.80 \pm \\
0.37\end{array}$ & $\begin{array}{l}2.20 \pm \\
0.58^{\star \star}\end{array}$ & $\begin{array}{l}2.10 \pm \\
0.43^{\star \star}\end{array}$ & $\begin{array}{l}1.31 \pm \\
0.13\end{array}$ \\
\hline $\begin{array}{l}\text { Cardiomyocyte } \\
\text { degeneration }\end{array}$ & 0 & $\begin{array}{l}4.80 \pm \\
0.37 \star\end{array}$ & $\begin{array}{l}8.60 \pm \\
0.50\end{array}$ & $\begin{array}{l}4.40 \pm \\
0.50 \star \star\end{array}$ & $\begin{array}{l}4.30 \pm \\
0.48^{\star \star}\end{array}$ & $\begin{array}{l}1.42 \pm \\
0.35\end{array}$ \\
\hline $\begin{array}{l}\text { Cardiac nucleus } \\
\text { eccentric }\end{array}$ & 0 & $\begin{array}{l}5.00 \pm \\
0.44^{\star}\end{array}$ & $\begin{array}{l}9.00 \pm \\
0.44\end{array}$ & $\begin{array}{l}4.00 \pm \\
0.70^{\star \star \star}\end{array}$ & $\begin{array}{l}3.90 \pm \\
0.65^{\star \star}\end{array}$ & $\begin{array}{l}1.40 \pm \\
0.44\end{array}$ \\
\hline \multicolumn{7}{|c|}{$\begin{array}{l}\text { OVX: ovariectomized group, OD: ovariectomized with 8-weeks diabetic group. ODS: ovariectomized } \\
\text { diabetic group with 8-weeks swimming training. ODG: ovariectomized diabetic group with 8-weeks } \\
\text { genistein administration. ODGS: ovariectomized diabetic group with 8-weeks swimming training and } \\
\text { genistein administration. A minimum of ten fields for each heart slide were examined and assigned } \\
\text { for severity of injury based on numbers of } 10 \text { microscopic field. Data is expressed as mean } \pm \text { SEM. }\end{array}$} \\
\hline \multicolumn{7}{|c|}{ * $p<0.05$ vs. Sham \& OD; } \\
\hline \multicolumn{7}{|c|}{$\star \star p<0.05$ vs. Sham \& OVX \& OD \& ODGS. } \\
\hline
\end{tabular}

\section{Discussion}

The present study results showed that estrogen deprivation in the ovariectomy model of rats induces cardiac oxidative stress and inflammation, characterized by increasing levels of MDA, OSI, TOS, TNF- a, and NF-KB levels and reduction in TAC in cardiac tissue. Moreover, ovariectomy also reduced the 
expression of miRNA-133, Bcl-2, and IGF-1 in the heart of OVX compared with the sham group while increased Bax protein as an apoptotic marker. Diabetes potentiated the effects of ovariectomy on the parameters mentioned above. Genistein increased the cardiac expression of the miRNA-133 gene, Bcl-2, and IGF-1 protein level in ODG compared with the OD group. Genistein also improved oxidative and inflammation conditions. Furthermore, the combined intervention of genistein and exercise improved cardiovascular disease risk factors by increasing miRNA-133 gene, Bcl-2, and IGF-1 protein expressions along with a reduction in Bax protein in the heart of ODGS compare with sham and OD groups. The combined intervention also was associated with antioxidant and anti-inflammation effects.

Diabetic women who have experienced menopause are more at risk of cardiovascular disease than nonmenopausal women (Zhou et al. 2019). Recent investigations have indicated that abnormal expression of microRNAs and enhancement of oxidative stress, apoptosis, and inflammation are important risk factors in the pathogenesis of diabetic cardiomyopathy (Khullar et al. 2010). Thus finding therapeutic approaches that manage these processes have gained attention. Previous studies suggest that the phytoestrogen genistein has beneficial effects against oxidative stress and cardiac inflammation in diabetic cardiomyopathy (Gupta et al. 2015; Weng et al. 2019). Genistein also improves cardiovascular risk factors in postmenopausal women (Crisafulli et al. 2005). However, the effect of genistein on diabetic cardiomyopathy in ovariectomized rats is not well studied.

Using numerous mechanisms, miRNA-133 seems to adjust apoptosis and fibrosis in cardiomyocytes. In this regard, Chen et al. reported that reduction in myocardial expression of miRNA-133 led to an augmented expression of fibrosis markers in streptozotocin-induced diabetic cardiomyopathy (Chen et al. 2014). On the other hand, Yildrime and co-workers demonstrated the crucial influence of low expression of miRNA-133 in enhancing oxidative stress in the diabetic heart (Yildirim et al. 2013). Moreover, mitochondrial-mediated apoptosis has been shown to contribute to diabetic cardiomyopathy (Cai and Kang 2003). Bcl-2 is an essential anti-apoptotic protein that blocks cytochrome $\mathrm{c}$ release and prevents apoptosis (Hardwick and Soane 2013), and miRNA-133 as an anti-apoptotic microRNA increases the expression of Bcl-2.

Moreover, in a previous study, we reported that miRNA-133 and Bcl-2 downregulated in the heart of OD rats compared to the sham group (Habibi et al. 2016b). Although, Braxas et al. reported the improving effect of genistein on some cardiovascular risk factors in postmenopausal women with Type 2 diabetes (Braxas et al. 2020), the effect of genistein on the expression of miRNA-133 and its targets genes in the heart of diabetic ovariectomized rats had not been studied. Our result showed that genistein restored diabetes-induced reduction in heart miRNA-133 and Bcl-2 expression. Genistein also reduced oxidative stress and inflammation (MDA, OSI, TOS and TNF-a, NF-KB) and Bax expression while increased TAC along with up-regulation of Bcl-2 protein level.

Our obtained results also showed that genistein treatment increases IGF-1 protein level in the ODG group compared to the OD group. IGF-1 has been shown to activate the phosphatidylinositol 3 kinase-Akt (PI3K-Akt) pathway and regulates cardiac metabolism, hypertrophy, and apoptosis (Wang et al. 2016). 
Correlation between miRNA-133 and IGF-1 in diabetic cardiovascular complications has been shown in previous studies. For example, in cultured neonatal cardiomyocytes, miRNA-133 improved high glucoseinduced cardiomyocyte hypertrophy by preventing high glucose-induced upregulation of IGF-1 receptors (Feng et al. 2010). On the other hand, overexpression of miRNA-133a decelerates IGF-1 deficiencyinduced hypertrophy in neonatal rat cardiomyocytes (Hua et al. 2012).

Furthermore, overexpression of IGF-1 or its receptor attenuated diabetic cardiomyopathy through inhibition of oxidative stress and fibrosis (Huynh et al. 2010; Kajstura et al. 2001). Wang et al. reported that the improving effect of IGF-1 on diabetic cardiomyopathy includes the reduced oxidative stress and inflammation along with an activation of the PI3K/Akt/GSK3ß signaling pathway (Wang et al. 2016). On the other hand, Nguyen and co-workers' study reported that genistein treatment affects the expression of cardiovascular IGF-1 in ovariectomized rats (Nguyen et al. 2013), which is in line with our present results. It is possible that genistein leads to enhancement of miRNA-133 and Bcl-2 levels, therefore reducing cell death in cardiomyocytes. Therefore, our results indicate that genistein treatment increases the expression of miRNA-133 and its target genes, IGF-1 and Bcl-2, and improves cardiac function.

Evidence indicates a similar effect between genistein and exercise training on common markers of cardiac function in animal models of ovariectomy (Gupta et al. 2015; Habibi et al. 2020). Moreover, we have previously shown that an eight-week swimming program reduced cardiomyopathy and increased miRNA-133 and Bcl-2 expression in diabetic ovariectomized rats (Habibi et al. 2020). Thus, in the second part of our study, we examined the possible cooperative effects of genistein and exercise training on diabetes-induced cardiac dysfunction. Obtained results indicated that combination treatment with genistein and exercise training showed additive effects on cardiac oxidative stress and expression of miRNA-133, IGF-1, and Bcl-2 in diabetic ovariectomized rats in comparison with genistein treated or exercised diabetic ovariectomized animals. The results of our study differ from those previously published by Al-nakkash et al. that reported no improvement on cardiovascular factors in ovariectomized rats under co-treatment of genistein and exercise training (Al-Nakkash et al. 2014). In contrast, this result was in agreement with the results obtained by Lee and co-workers' study, in which the combination of soy isoflavone and exercise improves defensive influences on cardiovascular diseases in ovariectomized rats (Lee et al. 2012). It should be noted that genistein exerts dose-dependent effects on cardiac gene expression and function in disease and intact heart (Nguyen et al. 2013).

Besides, during the eight weeks, swimming training or/and genistein induction, the profile of lipid improvement, FBG, insulin, and HGA1c were other important issues that might intensify the danger of cardiovascular diseases in diabetic postmenopausal women. Furthermore, H\&E and PAS assay findings revealed that the abnormal tissue architecture, fragmentation, and irregular accumulation of glycogen granules in the heart of $O$ and OD improved by eight weeks of exercise or genistein administration compared with those of the sham animal group. However, the combined intervention of exercise and genistein improved more the studied parameters in the related group. These data indicated that, in estrogen-deficient states, the combined intervention of regular moderate exercise and genistein administration was the most effective treatment to cardiac function and restored metabolic homeostasis. 
In the current study, we demonstrated the beneficial effects of the combined intervention of exercise and genistein on the improvement of plasma lipid profiles and the inhibition of cardiac apoptosis and fibrosis against estrogen deficiency by OD.

In conclusion, the combined intervention of exercise and genistein appears to have a significant influence on inhibiting the growth of cardiovascular risk factors.

\section{Declarations}

Acknowledgments: The authors would like to express their gratitude to the Drug Applied Research Center, Tabriz University of Medical Sciences, Tabriz, Iran.

Code availability:Not applicable

Authors' contributions: $\mathrm{PH}, \mathrm{MM}$ and $\mathrm{FN}$ designed experiments and analyzed data; $\mathrm{AV}, \mathrm{AS}$ and $\mathrm{MKH}$ performed the experiments; FN wrote the manuscript with substantial contributions of $\mathrm{PH}$ and $\mathrm{MM}$. The authors declare that all data were generated in-house and that no paper mill was used

Funding: This research was supported by a grant (Grant number: 5/79/4530) from the Tabriz University of Medical Sciences.

Data availability: Original and raw data containing all individual data points are available as supplemental data, for experiments performed with organ bath and by RT-PCR.

Competing interests: The authors declare that they have no competing interests.

Ethics approval and consent to participate: All experimental procedures using rats were conducted by the animal care and use guidelines approved by the institutional ethics committee at Tabriz University of Medical Sciences and were performed following the National Institutes of Health Guide for Care and Use of Laboratory Animals.

Consent for publication: Non applicable.

\section{References}

1. Al-Nakkash L, Janjulia T, Peterson K, Lucy D, Wilson D, Peterson A et al (2014) Genistein and exercise do not improve cardiovascular risk factors in the ovariectomized rat. Climacteric 17: 136-147

2. Boudina S \& Abel E D (2010) Diabetic cardiomyopathy causes and effects. Reviews in Endocrine and Metabolic Disorders 11: 31-39

3. Braxas H, Rafraf M, Hasanabad S K \& Jafarabadi M A (2020) Genistein supplementation improves some cardiovascular risk factors in postmenopausal women with Type 2 diabetes mellitus. Nutrition \& Food Science 
4. Cai L \& Kang Y J (2003) Cell death and diabetic cardiomyopathy Cardiovascular toxicology 3: 219228

5. Chen H-S, Shan Y-X, Yang T-L, Lin H-D, Chen J-W, Lin S-J et al (2005) Insulin deficiency downregulated heat shock protein 60 and IGF-1 receptor signaling in diabetic myocardium. Diabetes 54: $175-181$

6. Chen S, Puthanveetil P, Feng B, Matkovich S J, Dorn G W \& Chakrabarti S (2014) Cardiac miR-133a overexpression prevents early cardiac fibrosis in diabetes. Journal of cellular and molecular medicine 18: $415-421$

7. Chiyomaru T, Yamamura S, Fukuhara S, Hidaka H, Majid S, Saini S et al (2013) Genistein upregulates tumor suppressor microRNA-574-3p in prostate cancer. PLoS One 8: e58929

8. Crisafulli A, Altavilla D, Marini H, Bitto A, Cucinotta D, Frisina N et al (2005) Effects of the phytoestrogen genistein on cardiovascular risk factors in postmenopausal women. Menopause 12: 186-192

9. Daghigh F, Alihemmati A, Karimi P, Habibi P \& AhmadiasI N (2017) Genistein preserves the lungs of ovariectomized diabetic rats: addition to apoptotic and inflammatory markers in the lung. Iranian journal of basic medical sciences 20: 1312

10. Daghigh F, Alihemmati A, Karimi P, Habibi P \& AhmadiasI N (2018) Fibrotic and apoptotic markers alteration in ovariectomised rats: addition of swimming training preserves lung architecture. Archives of physiology and biochemistry 124: 286-291

11. Dixon R A \& Ferreira D (2002) Molecules of Interest: Genistein ChemInform 33: no-no

12. Ellison G M, Waring C D, Vicinanza C \& Torella D (2011) Physiological cardiac remodelling in response to endurance exercise training: cellular and molecular mechanisms. Heart heartjnl-2011300639

13. Feng B, Chen S, George B, Feng Q \& Chakrabarti S (2010) miR133a regulates cardiomyocyte hypertrophy in diabetes. Diabetes/metabolism research and reviews 26: 40-49

14. Fernandes T, Magalhães F C, Roque F R, Phillips M I \& Oliveira E M (2012) Exercise training prevents the microvascular rarefaction in hypertension balancing angiogenic and apoptotic factors role of microRNAs-16-21 and-126. Hypertension 59: 513-520

15. Ghosh N \& Katare R (2018) Molecular mechanism of diabetic cardiomyopathy and modulation of microRNA function by synthetic oligonucleotides. Cardiovascular diabetology 17: 1-25

16. Gilbert E R \& Liu D (2013) Anti-diabetic functions of soy isoflavone genistein: mechanisms underlying its effects on pancreatic $\beta$-cell function. Food \& function 4: 200-212

17. Gupta S K, Dongare S, Mathur R, Mohanty I R, Srivastava S, Mathur S et al (2015) Genistein ameliorates cardiac inflammation and oxidative stress in streptozotocin-induced diabetic cardiomyopathy in rats. Molecular and cellular biochemistry 408: 63-72

18. Habibi P, Alihemmati A, AhmadiasI N, Fateh A \& Anvari E (2020) Exercise training attenuates diabetes-induced cardiac injury through increasing miR-133a and improving pro-apoptosis/antiapoptosis balance in ovariectomized rats. Iranian journal of basic medical sciences 23: 79 
19. Habibi P, Alihemmati A, NourAzar A, Yousefi H, Mortazavi S \& Ahmadiasl N (2016) Expression of the Mir-133 and Bcl-2 could be affected by swimming training in the heart of ovariectomized rats. Iranian journal of basic medical sciences 19: 381

20. Habibi P, Alihemmatti A, Alipour M, Nourazar A, Yousefi H, Andalib S et al (2016) Effects of exercise on mir-29 and igf-1 expression and lipid profile in the heart of ovariectomized rat. Acta Endocrinologica (Bucharest) 12: 130

21. Habibi P, Babri S, Ahmadiasl N \& Yousefi H (2017) Effects of genistein and swimming exercise on spatial memory and expression of microRNA 132 BDNF and IGF-1 genes in the hippocampus of ovariectomized rats. Iranian journal of basic medical sciences 20: 856

22. Hardwick J M \& Soane L (2013) Multiple functions of BCL-2 family proteins Cold Spring Harbor perspectives in biology 5: a008722

23. Hua Y, Zhang Y \& Ren J (2012) IGF-1 deficiency resists cardiac hypertrophy and myocardial contractile dysfunction: role of microRNA-1 and microRNA-133a. Journal of cellular and molecular medicine 16: 83-95

24. Huynh K, McMullen J R, Julius T L, Tan J W, Love J E, Cemerlang N et al (2010) Cardiac-specific IGF1 receptor transgenic expression protects against cardiac fibrosis and diastolic dysfunction in a mouse model of diabetic cardiomyopathy. Diabetes 59: 1512-1520

25. Izarra A, Moscoso I, Levent E, Cañón S, Cerrada I, Díez-Juan A et al (2014) miR-133a enhances the protective capacity of cardiac progenitors cells after myocardial infarction. Stem cell reports 3: 10291042

26. Kajstura J, Fiordaliso F, Andreoli A M, Li B, Chimenti S, Medow M S et al (2001) IGF-1 overexpression inhibits the development of diabetic cardiomyopathy and angiotensin II-mediated oxidative stress. Diabetes 50: 1414-1424

27. Kanter M, Aksu F, Takir M, Kostek O, Kanter B \& Oymagil A (2017) Effects of low intensity exercise against apoptosis and oxidative stress in Streptozotocin-induced diabetic rat heart. Experimental and Clinical Endocrinology \& Diabetes 125: 583-591

28. Katz M G, Fargnoli A S, Kendle A P, Hajjar R J \& Bridges C R (2016) The role of microRNAs in cardiac development and regenerative capacity. American Journal of Physiology-Heart and Circulatory Physiology 310: H528-H541

29. Khullar M, Al-Shudiefat A A-R S, Ludke A, Binepal G \& Singal P K (2010) Oxidative stress: a key contributor to diabetic cardiomyopathy. Canadian journal of physiology and pharmacology 88: 233240

30. Lee J, Cho H-S, Kim D-Y, Cho J-Y, Chung J-S, Lee H-K et al (2012) Combined effects of exercise and soy isoflavone diet on paraoxonase nitric oxide and aortic apoptosis in ovariectomized rats. Appetite 58: $462-469$

31. Li N, Zhou H \& Tang Q (2018) miR-133: a suppressor of cardiac remodeling?. Frontiers in pharmacology 9903 
32. Liu X \& Liu S (2017) Role of microRNAs in the pathogenesis of diabetic cardiomyopathy. Biomedical reports 6: 140-145

33. Mahmoud A M (2017) Exercise amaliorates metabolic disturbances and oxidative stress in diabetic cardiomyopathy: possible underlying mechanisms. Exercise for Cardiovascular Disease Prevention and Treatment (pp 207-230): Springer

34. Naderi R, Mohaddes G, Mohammadi M, Ghaznavi R, Ghyasi R \& Vatankhah A M (2015) Voluntary exercise protects heart from oxidative stress in diabetic rats. Advanced pharmaceutical bulletin 5 : 231

35. Nguyen B T, Kararigas G \& Jarry H (2013) Dose-dependent effects of a genistein-enriched diet in the heart of ovariectomized mice. Genes \& nutrition 8: 383-390

36. O'Brien J, Hayder H, Zayed Y \& Peng C (2018) Overview of microRNA biogenesis mechanisms of actions and circulation. Frontiers in endocrinology 9402

37. Shantikumar S, Caporali A \& Emanueli C (2012) Role of microRNAs in diabetes and its cardiovascular complications. Cardiovascular research 93: 583-593

38. Thangavel P, Puga-Olguín A, Rodríguez-Landa J F \& Zepeda R C (2019) Genistein as potential therapeutic candidate for menopausal symptoms and other related diseases. Molecules 24: 3892

39. Wang C Y, Li X D, Hao Z H \& Xu D (2016) Insulin-like growth factor-1 improves diabetic cardiomyopathy through antioxidative and anti-inflammatory processes along with modulation of Akt/GSK-3 $\beta$ signaling in rats. The Korean journal of physiology \& pharmacology: official journal of the Korean Physiological Society and the Korean Society of Pharmacology 20: 613

40. Weng L, Zhang F, Wang R, Ma W \& Song Y (2019) A review on protective role of genistein against oxidative stress in diabetes and related complications. Chemico-biological interactions 310108665

41. White R E, Gerrity R, Barman S A \& Han G (2010) Estrogen and oxidative stress: A novel mechanism that may increase the risk for cardiovascular disease in women. Steroids 75: 788-793

42. Xia J, Duan Q, Ahmad A, Bao B, Banerjee S, Shi Y et al (2012) Genistein inhibits cell growth and induces apoptosis through up-regulation of miR-34a in pancreatic cancer cells. Current drug targets 13: $1750-1756$

43. Xu L, Xiang J, Shen J, Zou X, Zhai S, Yin Y et al (2013) Oncogenic MicroRNA-27a is a target for genistein in ovarian cancer cells. Anti-Cancer Agents in Medicinal Chemistry (Formerly Current Medicinal Chemistry-Anti-Cancer Agents) 13: 1126-1132

44. Yildirim S S, Akman D, Catalucci D \& Turan B (2013) Relationship between downregulation of miRNAs and increase of oxidative stress in the development of diabetic cardiac dysfunction: junctin as a target protein of miR-1. Cell biochemistry and biophysics 67: 1397-1408

45. Youle R J \& Strasser A (2008) The BCL-2 protein family: opposing activities that mediate cell death Nature reviews Molecular cell biology 9: 47-59

46. Zhou H, Zhang C, Ni J \& Han X (2019) Prevalence of cardiovascular risk factors in non-menopausal and postmenopausal inpatients with type 2 diabetes mellitus in China. BMC endocrine disorders 19: $1-9$

Page 18/25 
Figures

\section{Level ( mg / dl )}

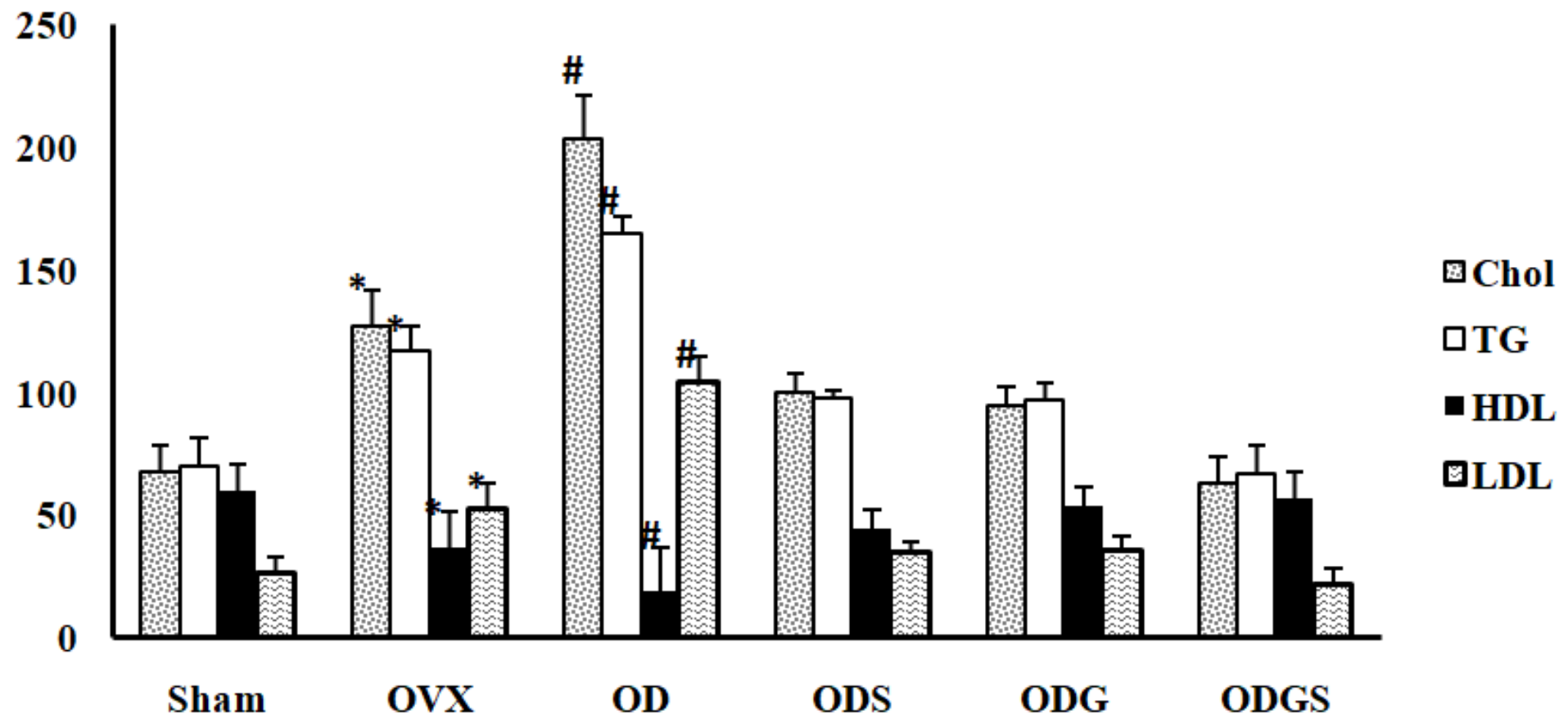

Figure 1

Effect of genistein treatment and/or swimming training in diabetic ovariectomized rats on triglycerides (TG), total cholesterol (Chol), high-density lipoprotein (HDL), low-density lipoprotein (LDL). OVX: ovariectomized group, OD: ovariectomized with 8-weeks diabetic group. ODS: ovariectomized diabetic group with 8-weeks swimming training. ODG: ovariectomized diabetic group with 8-weeks genistein administration. ODGS: ovariectomized diabetic group with 8-weeks swimming training and genistein administration. Data are expressed as mean \pm SEM. * $(P<0.05)$ vs. Sham \& OD \& ODS; ** $(P<0.05)$ vs. Sham \& ODS; \# $(P<0.05)$ vs. Sham. Compared with the sham group, b compared with the 0 group, and $c$ compared with the OD group. ${ }^{*} p<0.05, \# p<0.001$. 
A

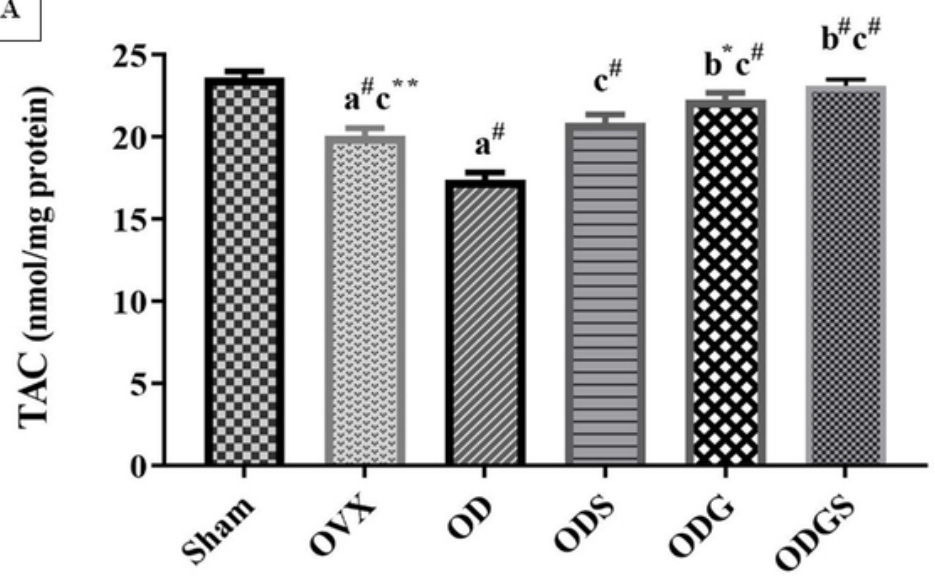

Groups

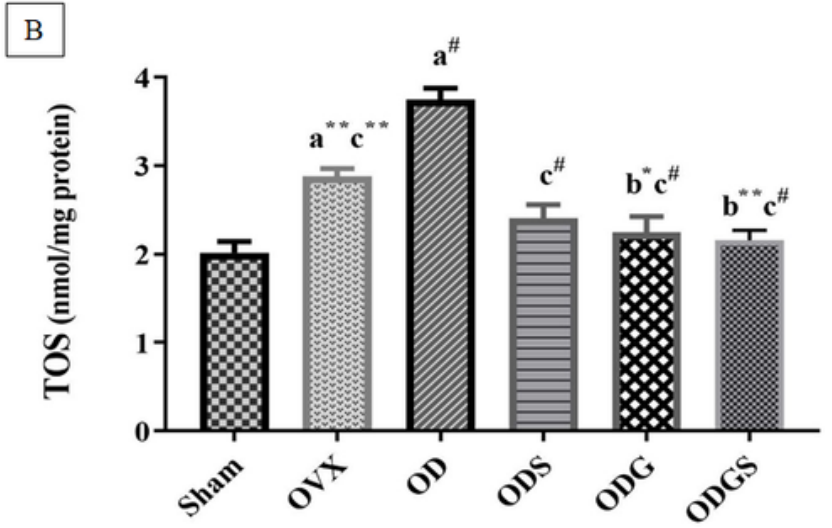

Groups

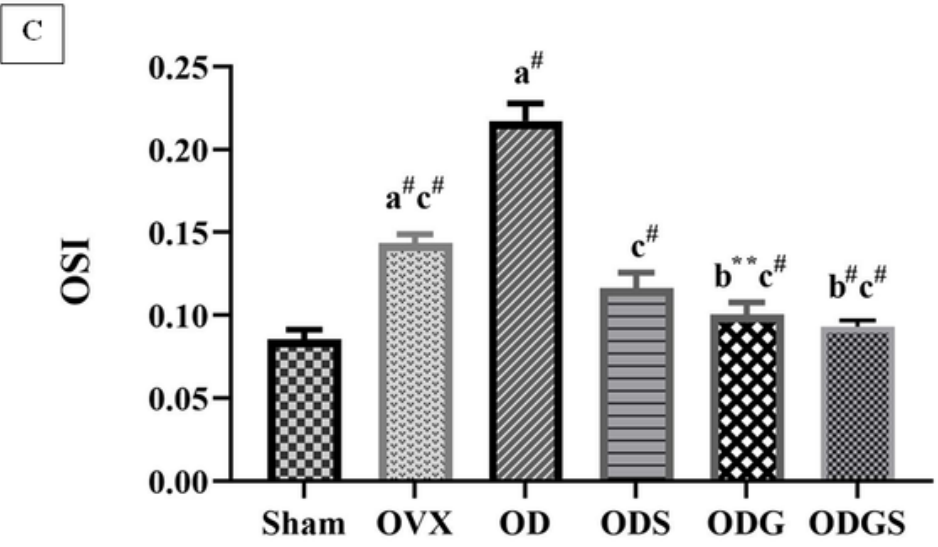

Groups

Figure 2

Effects of genistein treatment and/or swimming training in diabetic ovariectomized rats on Total Antioxidant Capacity (TAC; A), Total Oxidant Status (TOS; B), and Oxidative Stress Index (OSI; C) in heart homogenates. Data are expressed as mean \pm SEM. OVX: ovariectomized group, OD: ovariectomized with 8-weeks diabetic group. ODS: ovariectomized diabetic group with 8-weeks swimming training. ODG: ovariectomized diabetic group with 8-weeks genistein administration. ODGS: ovariectomized diabetic 


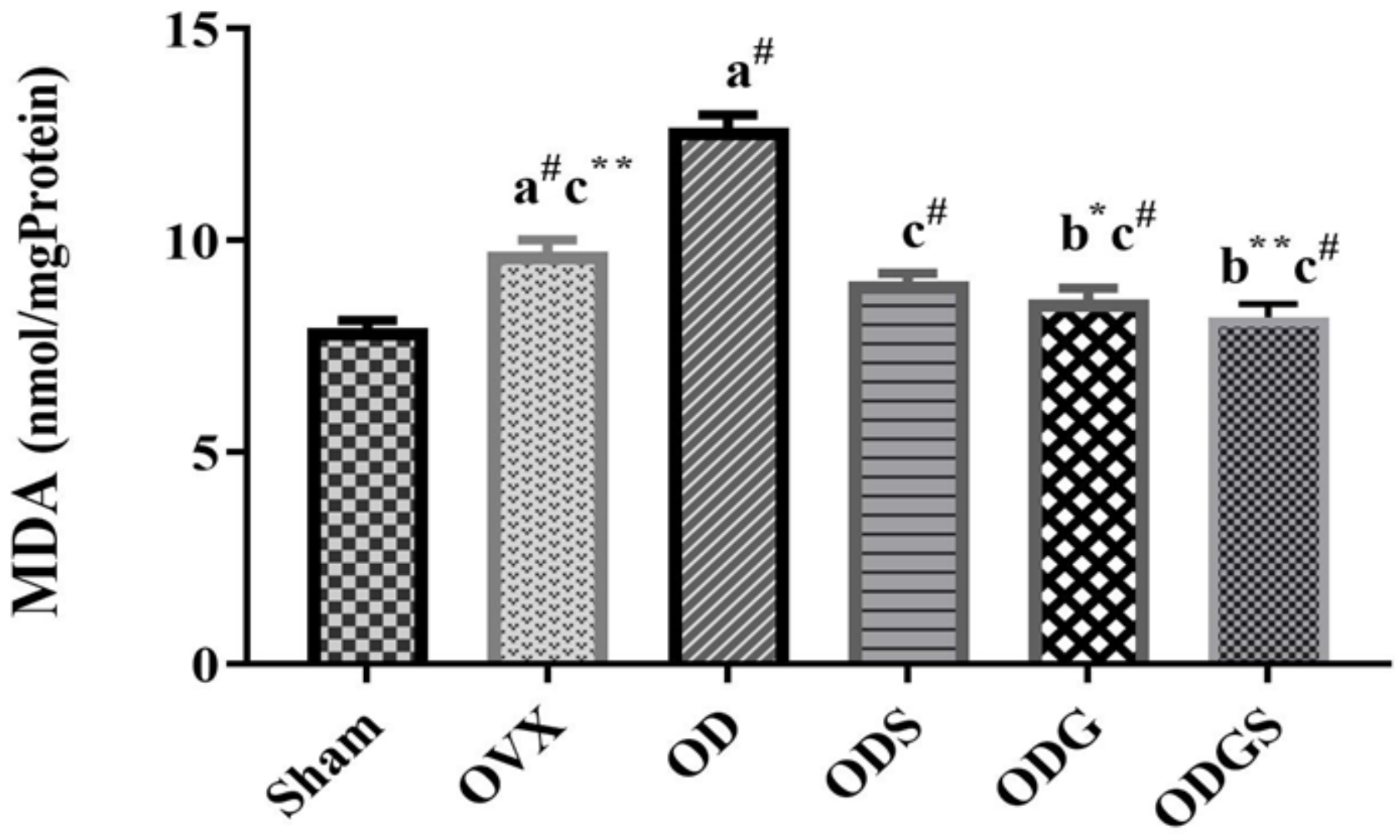

\section{Groups}

Figure 3

Effects of genistein treatment and/or swimming training in diabetic ovariectomized rats on lipid peroxidation (MDA concentration). Data are expressed as mean \pm SEM. OVX: ovariectomized group, OD: ovariectomized with 8-weeks diabetic group. ODS: ovariectomized diabetic group with 8-weeks swimming training. ODG: ovariectomized diabetic group with 8-weeks genistein administration. ODGS: ovariectomized diabetic group with 8-weeks swimming training and genistein administration. a as compared with the sham group, b compared with OVX group, and c compared with the OD group. ${ }^{*} p<0.05,{ }^{\star \star} p<0.01, \# p<0.001$. 

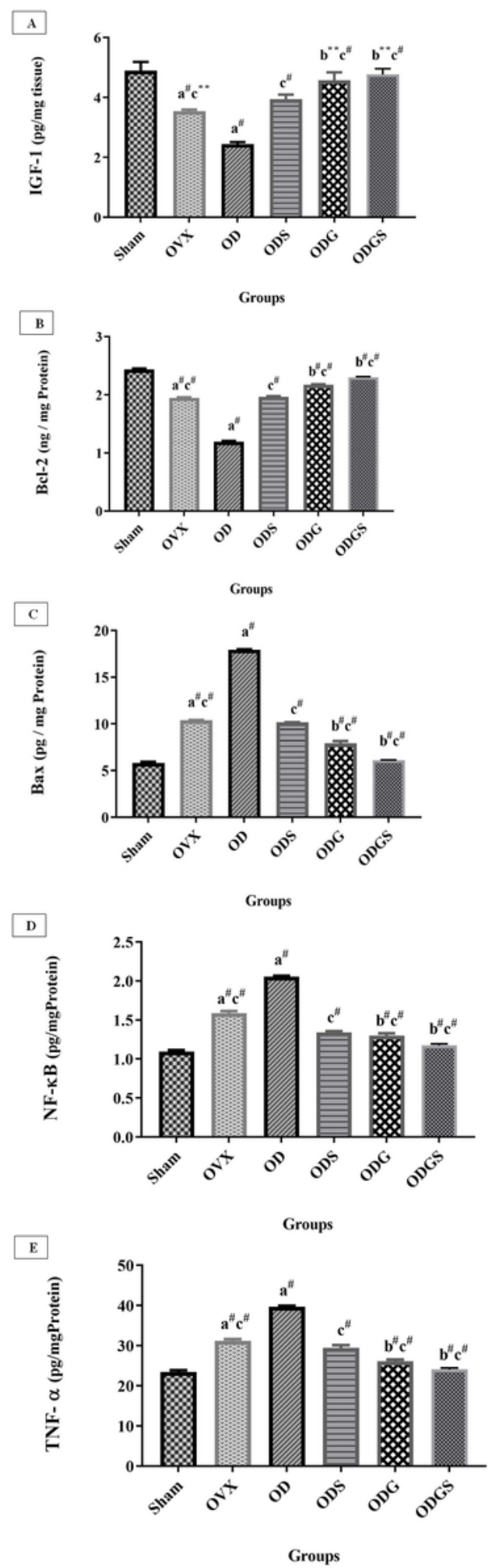

\section{Figure 4}

Effect of genistein treatment and/or swimming training in diabetic ovariectomized rats on IGF-1 (A), Bcl-2 $(B)$, and Bax (C), NF-KB (D), and TNF-a (E) protein concentrations. Data are expressed as mean \pm SEM. OVX: ovariectomized group, OD: ovariectomized with 8-weeks diabetic group. ODS: ovariectomized diabetic group with 8-weeks swimming training. ODG: ovariectomized diabetic group with 8-weeks genistein administration. ODGS: ovariectomized diabetic group with 8-weeks swimming training and 
genistein administration. a as compared with the sham group, b compared with OVX group, and c compared with the OD group. ${ }^{* *} \mathrm{p}<0.01, \# p<0.001$.
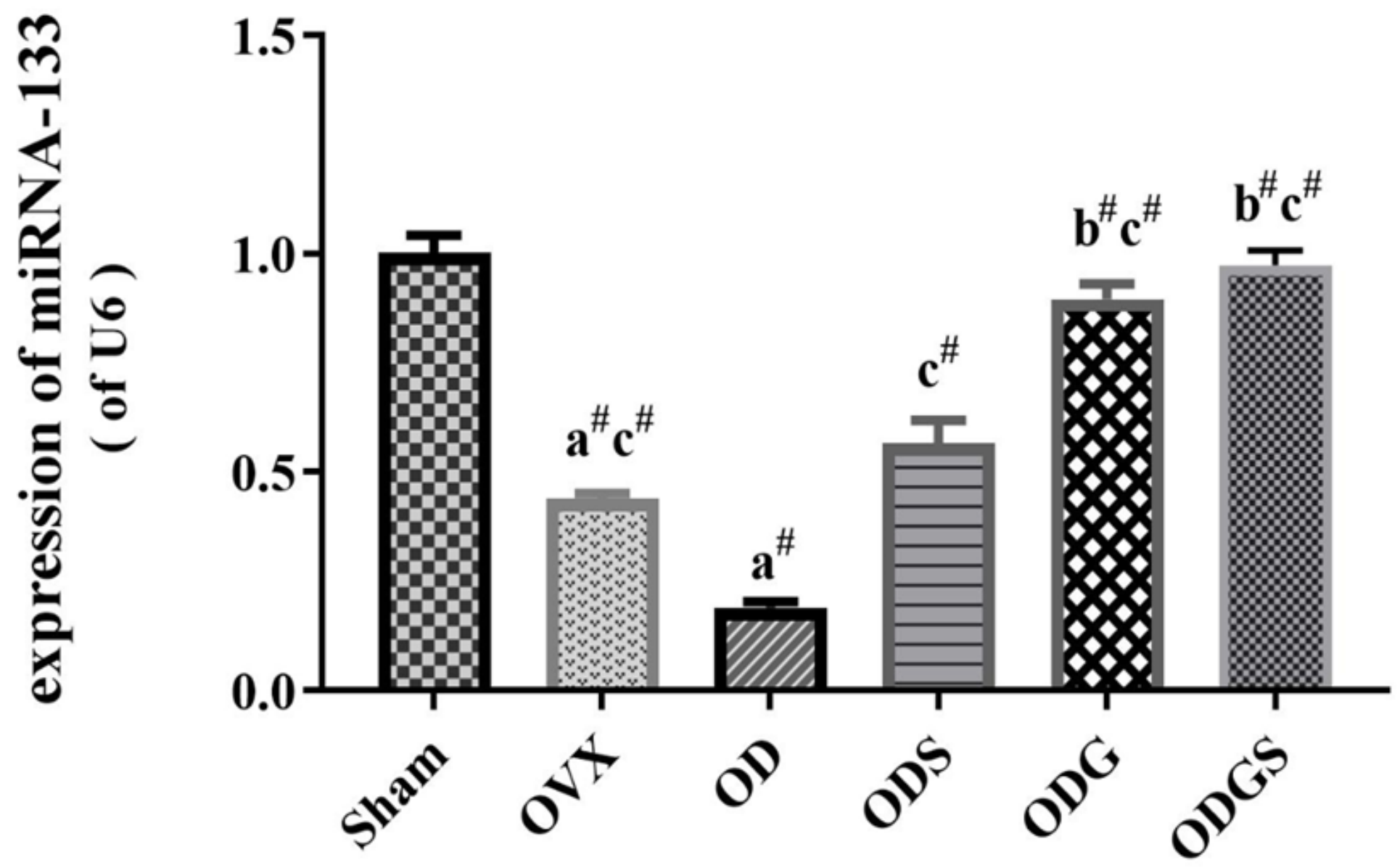

Figure 5

Quantitative analysis for the level of heart miRNA-133 expression under the treatments by Real-time PCR. Data are expressed as mean \pm SEM. OVX: ovariectomized group, OD: ovariectomized with 8-weeks diabetic group. ODS: ovariectomized diabetic group with 8-weeks swimming training. ODG: ovariectomized diabetic group with 8-weeks genistein administration. ODGS: ovariectomized diabetic group with 8-weeks swimming training and genistein administration. a as compared with the sham group, b compared with the OVX group, and c compared with the OD group. $\# p<0.001$. 

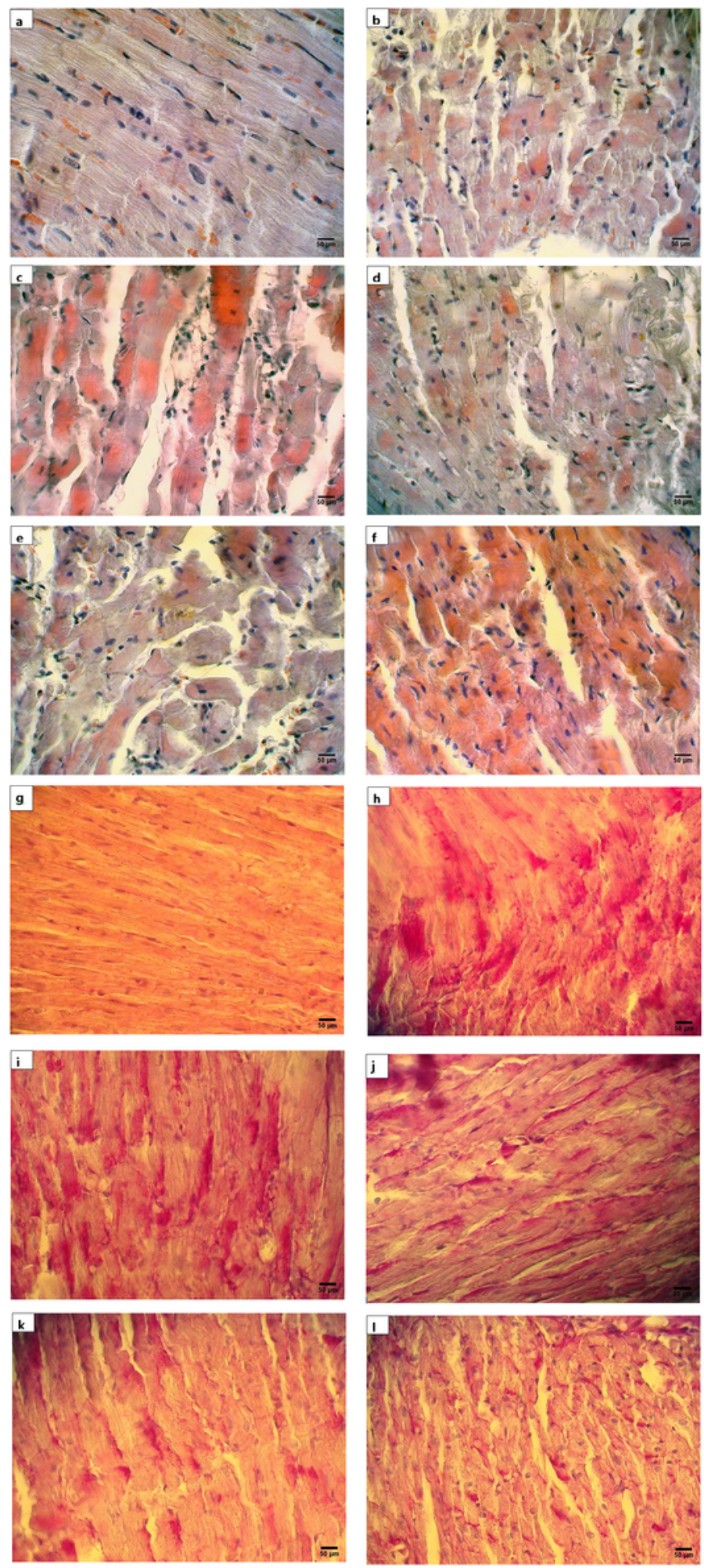

Figure 6

Histological changes have been represented in the Fig.6a-6l. Sham group (Fig. 6A), OVX group (Fig. 6B), OD group (Fig. 6C), ODG group (Fig. 6D), ODS group (Fig. 6E), ODGS group (Fig. 6F)in H\&E analysis. Sham group (Fig. 6G), OVX group (Fig. 6H), OD group (Fig. 6I),ODG group (Fig. 6J), ODS group (Fig. 6K), ODGS group (Fig. 6L) in PAS analysis. OVX: ovariectomized group, OD: ovariectomized with 8-weeks diabetic group. ODS: ovariectomized diabetic group with 8-weeks swimming training. ODG: 
ovariectomized diabetic group with 8-weeks genistein administration. ODGS: ovariectomized diabetic group with 8-weeks swimming training and genistein administration.

\section{Supplementary Files}

This is a list of supplementary files associated with this preprint. Click to download.

- heartdata.xlsx 